\title{
REFLEXÕES SOBRE ESTUDOS DE GÊNERO NO PLANO MUNICIPAL DE EDUCAÇÃO DE CAMPO GRANDE/MS E OS DIÁLOGOS COM A HISTÓRIA ENSINADA
}

\author{
Jaqueline Ap. M. Zarbato ${ }^{1}$ \\ Vivina Dias Sol Queiroz ${ }^{2}$
}

\begin{abstract}
Resumo: Este artigo tem por objetivo refletir sobre os debates que fundamentaram o Plano Municipal de Educação, em Campo Grande/MS, (2015-2025), tendo em sua análise os 'embates' sobre a promulgação do documento, com as controvérsias sobre a inserção da abordagem e conceito de gênero. Faz-se uma discussão do PME de Campo Grande, principiando em abordar as notícias jornalísticas, a retirada do conceito de gênero influenciado pelos debates 'religiosos'. Assim, dividimos a análise em dois momentos: a primeira parte em que analisamos o teor do documento, suas metas para a abordagem de gênero, no Ensino Fundamental e Médio, bem como as discussões sobre a retirada do termo de gênero do PME/MS, bem como as notícias jornalísticas que circularam. E, num segundo momento, lançamos a reflexão sobre as concepções teóricas de gênero e que contribuem para a compreensão histórico-cultural dos grupos que vivenciam o espaço escolar.
\end{abstract}

Palavras-chaves: gênero, plano municipal de educação, história.

\section{REFLECTIONS ON GENDER IN THE MUNICIPAL PLAN OF EDUCATION OF CAMPO GRANDE / MS AND THE DIALOGUES WITH HISTORY TAUGHT.}

\begin{abstract}
This article aims to reflect on the debates that underpinned the Municipal Plan of Education, in Campo Grande / MS, analyzing the 'struggles' on the promulgation of the document, with the controversies about the insertion of the gender approach. There is a discussion of the PME in Campo Grande, beginning with addressing the news stories, the withdrawal of the concept of gender influenced by 'religious' debates. Thus, we divided the analysis into two moments: the first part in which we analyzed the content of the document, its goals for the gender approach in Elementary and Middle School, as well as the discussions about the gender withdrawal of PME / MS, as well as The news stories that circulated. And, in a second moment, we launch the reflection on the theoretical conceptions of gender and that contribute to the historical-cultural understanding of the groups that experience the school space.
\end{abstract}

Keywords: Gender, municipal education plan, history.

\footnotetext{
1 Doutora em História. Professora na Universidade Federal de Mato Grosso do Sul (UFMS). E-mail: jaqueline.zarbato@gmail.com

2 Doutora em Educação. Professora na Universidade Federal de Mato Grosso do Sul (UFMS). E-mail: vivinasol@gmail.com
} 


\section{REFLEXIONES SOBRE ESTUDIOS DE GÉNERO EN EL PLAN MUNICIPAL DE EDUCACIÓN DE CAMPO GRANDE / MS Y LOS DIÁLOGOS CON LA HISTORIA ENSEÑADA}

Resumen: Este artículo tiene por objetivo reflexionar sobre los debates que fundamentaron el Plan Municipal de Educación, en Campo Grande / MS, (2015-2025), teniendo en su análisis los 'embates' sobre la promulgación del documento, con las controversias sobre la promulgación la inserción del enfoque y el concepto de género. Se hace una discusión de lo PME de Campo Grande, comenzando en abordar las noticias periodísticas, la retirada del concepto de género influenciado por los debates 'religiosos'. Así, dividimos el análisis en dos momentos: la primera parte en que analizamos el contenido del documento, sus metas para el abordaje de género, en la Enseñanza Fundamental y Medio, así como las discusiones sobre la retirada del término de género de la PME/MS, así como las noticias periodísticas que circularon. Y, en un segundo momento, lanzamos la reflexión sobre las concepciones teóricas de género y que contribuyen a la comprensión histórico-cultural de los grupos que vivencian el espacio escolar.

Palabras claves: género, plan municipal de educación, historia.

\section{CONTEXTUALIZANDO A DISCUSSÃO DE GÊNERO NO PLANO MUNICIPAL DE EDUCAÇÃO EM CAMPO GRANDE/MS}

[...] o termo ideologia de gênero (grifos nossos) classificaria que a sexualidade deve ser construída e escolhida. "Ou seja, eu nasci homem, mas posso escolher ser mulher, o que a nosso ver é uma afronta à vontade de Deus (Correio do Estado, 23/06/2015)

Com esse argumento/fala, o grupo que defendia a retirada do texto sobre relações de gênero no Plano Municipal de Educação em Campo Grande, Mato Grosso do Sul, 'esbravejava' durante a sessão da câmara de vereadores, no dia 23 de junho de 2015. A dita 'ideologia de gênero' ${ }^{3}$ foi o teor das narrativas de representantes da Igreja Católica, mas precisamente a "Comunidade Católica Boa Nova". Ainda, de acordo com a reportagem do Jornal Correio do Estado: "Para os religiosos, ideologia de gênero 'destrói a família' e plano de educação emperra” (23/06/2015).

No diário oficial de Campo Grande(2015), há a informação sobre a sanção do PME, assinalando que:

\footnotetext{
${ }^{3}$ Esse termo 'ideologia de gênero' foi encunhado por alguns grupos, os quais defendem a ideia de que gênero é uma projeção de tudo aquilo o que a sociedade e a cultura esperam que seja típico do comportamento masculino e feminino. Em contraposição a identidade de gênero, que é um dos temas difundido pelos estudos de gênero.
} 
O prefeito de Campo Grande, Gilmar Olarte (PP), sancionou o Plano Municipal de Educação (PME), válido pelos próximos dez anos. O decreto foi publicado na edição desta quarta-feira (24) do Diário Oficial do município (Diogrande). O projeto foi aprovado sob polêmica na sessão de terça-feira (23) da Câmara Municipal. A identidade de gênero, tema que estava previsto para ser abordado nas escolas, foi retirada por pressão de entidades religiosas.

A afirmação de que a pressão de entidades religiosas, influenciaram na retirada do texto sobre gênero, aponta que estamos vivenciando a intervenção de um ‘tempo religioso' em questões culturais e sociais, pois a preocupação em abordar nas escolas a diversidade de gênero foi suprimida em detrimento de argumentos 'religiosos'.

Nesse sentido, todo o processo de construção do referido documento, passa a ser alvo de interferências de grupos externos, não levando em conta o percurso e a fundamentação dos envolvidos na construção do PME. Até porque, este estava em consonância com a aprovação do PNE, o qual definiu as necessidades de cada nível de ensino. Logo, coube aos Estados elaborarem seu Plano Estadual de Educação (PEE), e Planos Municipais de Educação (PME) sempre articulado com o PNE. No estado do Mato Grosso do Sul foi aprovado na Lei $\mathrm{n}^{\circ} 4.621$, de 22 de dezembro de 2014, com vistas a transformações qualitativas na educação, atendendo as demandas educacionais, sociais e culturais.

Há, segundo Saviani (1999, p 32) vários fatores básicos e fundamentais para a elaboração do Plano Municipal de Educação, tais como:

a) Efetuar um diagnóstico das necessidades educacionais a serem atendidas pelo Sistema de Ensino Municipal; b) Explicitar as diretrizes que orientarão a elaboração do plano, justificando as opções adotadas e as prioridades assumidas; c) Definir as metas a serem alcançadas distribuídas num cronograma que indique as etapas a serem vencidas ao longo do tempo de vigência do plano; d) Especificar, para cada setor e respectivas metas, os meios disponíveis e aqueles que deverão ser providos; e) Elaborar um quadro claro dos recursos financeiros disponíveis assim como das fontes de recursos adicionais de modo a assegurar o que foi planejado.

A organização do PME/MS levou em conta essas dimensões organizacionais, porém, recuou na implementação de política educacional voltada a questão de gênero, o que ficou evidente, quando da manifestação contrária. Mas, por que há tanta preocupação em reforçar o modelo patriarcal, em pleno século XXI? A liberdade ou igualdade de gênero é algo histórico, então por que o cerceamento? 
Estas e outras inquietações, nos inquietam, quando nos deparamos com este tipo de reportagem, em que termos e definições relacionadas às relações de gênero perpassam as páginas de jornais. E, principalmente, em que os discursos sobre o encaminhamento do que a escola deveria trabalhar com as questões de gênero, influenciando inclusive os documentos legais, como o Plano Nacional de Educação e os Planos Estaduais e Municipais. Cabe lembrar, que estes documentos são norteadores das discussões sobre os temas abordados no cotidiano escolar e, como tal tem uma longa duração de pesquisas, debates, enfoques dos profissionais da Educação. E identidade de gênero ${ }^{4}$ passou a ser um assunto de destaque nos Planos Educacionais, devido a necessidade premente da sociedade moderna, das novas configurações sociais e culturais. Para Joana Pedro, "o que se nega agora é que as diferenças marquem o comportamento sexual das pessoas por toda a vida. Na verdade, o que se pede é a desaparição da noção de identidade de gênero (PEDRO, 2011, p 275). A autora ainda apresenta a análise sobre a discussão de identidade de gênero, argumentando que Judith Butler, por exemplo, sustenta que a identidade de gênero é útil à dominação masculina. Quando, em 1990, ela propôs a "performatividade do gênero", afirmou que gênero é uma construção cultural e que, portanto, não é resultado do sexo nem tão aparentemente fixo como o sexo. (PEDRO, 2011, p 275)

Mas também passou a ser apontado por alguns grupos religiosos, erroneamente como "ideologia de gênero".

O plano municipal de educação (2015-2025) contou com um grupo de profissionais da Educação que projetaram as abordagens e discussões, com várias fases, entre elas: "a Análise Situacional do Plano, Escrita e Adequação do Texto Base, relacionando com o Plano Estadual e com o Nacional de Educação. Assim, com o objetivo de eleger 140 delegados e 67 suplentes para representar vários segmentos da sociedade". Foi realizado o Seminário Livre sobre o Plano Municipal de Educação (PME), no Espaço de Formação Lúdio Martins Coelho, dia 16 de março de 2015, promovido pela Secretaria Municipal de Educação - SEMED.

Neste sentido, o percurso de fundamentação das questões relacionadas ao Plano, vem sendo discutido em âmbito nacional. E isso está ratificado no Plano Municipal de Educação, que em seu artigo $1^{\circ}$, destaca que:

Fica aprovado o Plano Municipal de Educação - PME do município de Campo Grande/MS, com vigência até 2025, de acordo com o estabelecido no Plano

\footnotetext{
${ }^{4}$ Cabe destacar, que a identidade de gênero, apresentada aqui, configura-se como a identificação com um dos papéis de gênero. Isso porque, as pessoas possuem uma identidade de gênero, que independe de sua orientação sexual, ou melhor, todas as pessoas tem pertencimento a um gênero.
} 
Nacional de Educação, na forma do Anexo, com vistas ao cumprimento do disposto no art. 214 da Constituição Federal, em consonância com a Lei Federal n. 13.005/2014 que aprovou o Plano Nacional de Educação (PNE) e a Lei Estadual n. 4.621/2014 que aprovou o Plano Estadual de Educação (PEE - MS-2014).

Logo, fica evidente que o processo de reflexão sobre as modificações na política educacional estão sendo encadeadas, num processo micro e macro. O que nem sempre contempla a diversidade de questões implícitas no campo educacional. Mas, embora tenhamos uma análise crítica sobre a tramitação e discussão do Plano Municipal de Educação, é importante analisar a construção deste, uma vez que encaminhou diretrizes para a formação dos sujeitos na prática educativa. Ao analisar o PME/MS, percebe-se que em seu art $2^{\circ}$, define as diretrizes, as quais pontuam:

I - erradicação do analfabetismo; II - universalização do atendimento escolar; III - superação das desigualdades educacionais, com ênfase na promoção da cidadania e na erradicação de todas as formas de discriminação; IV - melhoria da qualidade da educação; V - formação para o trabalho e para a cidadania, com ênfase nos valores morais e éticos em que se fundamenta a sociedade; VI - promoção do princípio da gestão democrática da educação pública; VII promoção humanística, científica, cultural e tecnológica do País; VIII estabelecimento de meta de aplicação de recursos públicos em educação como proporção do Produto Interno Bruto - PIB, que assegure atendimento às necessidades de expansão, com padrão de qualidade e equidade; IX valorização dos (as) profissionais da educação; X - promoção dos princípios do respeito aos direitos humanos, à diversidade e à sustentabilidade socioambiental ( PME, 2015).

Os trechos grifados no documento mostram alguns encaminhamentos para a inserção da abordagem acerca da realidade educacional e social de muitos estudantes. E de certa forma, visam garantir a formação nos elementos que promovem a diversidade, a ética, os direitos humanos. Assim, no processo de construção da proposta, que enfocava no trabalho efetivo, “com as 79 escolas públicas que ofertam a educação em tempo integral, englobando escolas com dois turnos" (PME/MS, 2015, p 20).

O discurso em torno da 'melhoria' da educação, ainda está vinculado aos programas, e não efetivamente as políticas públicas de educação. Percebe-se que, mesmo os discursos para o processo educacional preocupam-se mais com as estatísticas, do que propriamente com o ensino aprendizagem, como a inserção da educação em tempo integral. Porém, mesmo em que tempo integral, as abordagens didático-pedagógicas se enfocam, ainda, nas disciplinas eletivas. 
Pensando na superação disso, a fundamentação dos grupos de profissionais da Educação que atuaram no processo de construção do Plano Municipal de Educação, foi inserir temas e abordagens sobre a diversidade de gênero e sexual. Até mesmo porque, estavam seguindo a diretriz nacional, do PNE.

No documento preliminar do Plano Municipal de Educação, constava toda a argumentação para o trabalho com gênero e sexualidade nas escolas, principalmente pensando este como um espaço diverso, múltiplo, crítico, que deveria ter ações em prol da igualdade. Assim, conta no documento, a justificativa para a inserção do gênero, pois:

[...] a escola tem o papel imprescindível na democratização da sociedade, e suas estratégias de atuação devem abranger a todos. Assim, é preciso que a população LGBT tenha garantido o efetivo direito à educação, que é um conceito bem mais amplo do que o direito à escola. Direito à educação abrange não somente a escolarização e a abordagem de conteúdos sistematizados, mas sim a formação da cidadania do indivíduo, destacando a criatividade, a criticidade, as especificidades e enfatizando a qualidade de vida que cada um pode ter, como também garantindo a todos a igualdade de oportunidades. Por outro lado, é de extrema importância adotar ações para o enfrentamento da violência, em específico neste documento em ambiente escolar, contra lésbicas, gays, bissexuais, travestis, transgêneros e transexuais, uma vez que grande parte da evasão desses alunos refere-se justamente a esta violência sofrida, seja ela oral, física ou de cunho psicológico (PME,2015, p 06).

Percebe-se que, a escolarização deve ser vista também como espaço de demarcação das lutas pela cidadania, da garantia da igualdade para todos. E se não há um encaminhamento decisivo sobre as ações na escola, de que forma poderíamos abordar a diversidade de gênero e a sexualidade. Desta maneira, segundo Bock, Furtado \& Teixeira, (2001, p. 261). o papel da escola seria:

[...] transmitir a cultura e, com ela, modelos sociais de comportamento e valores morais, a escola permite que a criança "humanize-se", cultive-se, socialize-se ou, numa palavra, eduque-se. A criança, então, vai deixando de imitar os comportamentos adultos para, aos poucos, apropriar-se dos modelos e valores transmitidos pela escola, aumentando, assim, sua autonomia e seu pertencimento ao grupo social.

A importância em abordar a diversidade, identidade de gênero e sexualidade na escola tem um implicação sócio- cultural, uma vez que tem aumentado significativamente os índices 
de violência no Brasil, “até setembro de 2014 já foram assassinadas 218 pessoas. Esses dados incluem gays, lésbicas, travestis e transexuais (PME/MS, 2015, p 24).

Os pontos relevantes acerca da abordagem sobre gênero e sexualidade na escola, circunscritos no Plano Municipal de Educação levaram em conta as dimensões formativas das identidades de crianças e jovens brasileiros, no século XXI. Respeitando a democratização das relações e do sentimento de pertencimento de gênero.

Na meta 2, do Plano Municipal de Educação, para o Ensino Fundamental, consta:

2.14. fomentar e apoiar políticas de promoção de uma cultura de direitos humanos no ensino fundamental, pautada na democratização das relações, respeitando as diversidades de orientação sexual e identidade de gênero, e na convivência saudável com a comunidade escolar.

2.15. implementar políticas de prevenção à evasão, motivada por preconceito e discriminação racial, por orientação sexual ou identidade de gênero, criando rede de proteção contra formas associadas de exclusão.

2.16. promover ações pedagógicas com os alunos matriculados nas instituições de ensino públicas e privadas do município de Campo Grande/MS, com vistas à prevenção da violência sexista e homotransfóbica. (PME, 2015, p. 06)

Estas metas, nos fazem retomar o início deste texto, uma vez que em nenhum trecho do documento, explicita-se as 'ideologias de gênero'. O que nos leva a analisar os discursos impositivos de alguns grupos religiosos contrários ao PME, que tentam desqualificar as práticas de democratização das relações sociais, que impõem discursos fundamentalistas em meio ao processo educativo, o qual tem por cerne fomentar discussões sobre a cidadania, o direito, o respeito, a igualdade, que não levam em conta a importância das políticas públicas devem enfocar no processo de fundamentação das equidades. Como ressalta Joana Pedro (2011, p 275):

A categoria de análise "gênero" passa, portanto, por intenso bombardeio, e não só por ser acusada de ser útil à dominação. É também considerada desmobilizante para o feminismo. O que se reivindica é a retomada da categoria "mulher", não mais na perspectiva anterior, universal e determinada pela biologia (PEDRO, 2011, p. 275).

Ainda no PME/MS (2015), o texto da meta 3 para o Ensino Médio é ampliado, traz elementos que vão além do espaço escolar, o que demonstra a pertinência em fundamentar a discussão sobre gênero e sexualidade. Isso porque, nesta faixa etária há diferentes possibilidades de dialogar em grupos, de transpor as análises sobre gênero nos conteúdos 
escolares. Até mesmo na perspectiva de encaminhar a produção do conhecimento sobre as violações de direitos, violências psicológica, física e ou sexual, orientação sexual e identidade de gênero, entre outras. Guacira Louro (2011, p. 53), ao abordar a questão das identidades de gênero, aponta que quando afirmamos que as identidades de gênero e as identidades sexuais se constroem em relação queremos significar algo distinto e mais complexo do que uma oposição entre dois pólos; pretendemos dizer que as várias formas de sexualidade e de gênero são interdependentes, ou seja, afetam umas às outras (LOURO, 2011, p. 53).

Na abordagem do Ensino Médio, o PME, propôs, na meta 3:

3.3.1 assegurar que a Educação em Gênero e Sexualidade seja contemplada, como tema transversal, conforme estabelece o Plano Nacional de Promoção da Cidadania e Direitos Humanos.

3.8.3 garantir que as unidades escolares de Ensino Médio, no exercício de suas atribuições no âmbito da rede de proteção social, desenvolvam ações com foco na prevenção, detecção e encaminhamento das violações de direitos das crianças e adolescentes (violências psicológica, física e ou sexual, negligência, constrangimento, exploração do trabalho infanto-juvenil, uso indevido de drogas, discriminação racial, orientação sexual e identidade de gênero entre outras), por meio da inserção dessas temáticas no projeto político pedagógico e no cotidiano escolar, identificando, notificando e encaminhando os casos aos órgãos competentes.

3.13.2 implementar políticas de prevenção à evasão, motivada por preconceito e discriminação racial, por orientação sexual ou identidade de gênero, criando rede de proteção contra formas associadas de exclusão.

3.13.3 implementar ações de orientação e informação que assegurem o tratamento não diferenciado aos estudantes, funcionários e profissionais da educação, por motivo de orientação sexual ou identidade de gênero, a fim de evitar a evasão.

3.13.4 investir em campanhas educativas e informativas, voltadas para a conscientização da comunidade escolar quanto à população LGBT, a fim de promover o acolhimento humanizado de jovens e adolescentes LGBT nos ambientes escolares;

3.13.5 estabelecer mecanismos para diagnosticar, avaliar, monitorar, que permitam denúncias de atos homofóbicos e discriminatórios contra a população LGBT, nos ambientes escolares públicos e privados do município de Campo Grande/MS (PME, 2015, p 08).

Percebe-se que o texto amplia as abordagens de gênero, enfocando na inserção de mecanismos, que vão além do espaço educativo para implementar ações que asseguram o respeito à diversidade de gênero. Salientando que as escolas deveriam desenvolver ações com foco na prevenção, detecção e encaminhamento das violações de direitos das crianças e adolescentes, que vão desde as violências, explorações, preconceitos, discriminações. Esses elementos fundamentariam a busca pela superação das desigualdades, precisariam ser buscadas não nas diferenças biológicas (se é que mesmo essas podem ser compreendidas fora de sua constituição social), mas sim 
nos arranjos sociais, na história, nas condições de acesso aos recursos da sociedade, nas formas de representação (LOURO, 1997, p 22).

Pode-se dizer então, que o processo de construção dos documentos formativos, relacionados as políticas educacionais e, o que acarreta no sistema de ensino que reproduz de alguma maneira a desigualdade de gênero, ainda não foram totalmente inseridos. Na escola, temos um encaminhamento ainda tímido em relação a diversidade de gênero, talvez pela dificuldade de trazer para o centro das reflexões os significados de gênero subjacentes a essas desigualdades. Por isso, a inserção do gênero como constructo histórico dos sujeitos sociais deve ser a tônica das ações educacionais.

\title{
CONCEPÇÕES SOBRE GÊNERO NA ESCOLA E NA HISTÓRIA
}

É importante nos atermos a alguns termos que, de certa forma, pelo desconhecimento de alguns, causa estranhamento e até mesmo concepções errôneas acerca dos estudos das relações de gênero em sua historicidade. Isso porque, segundo Peter Stearns (2015, p. 47):

\begin{abstract}
Os desenvolvimentos durante o período clássico permitem perceber de que maneiras as trocas com os sistemas de valores alternativos podem afetar a questão de gênero- e particularmente a avaliação e os papéis das mulheres [...] os romanos podem ter notado umas poucas diferenças entre suas ideais sobre as mulheres e as que discerniram entre os gregos quando negociaram com eles e depois os conquistaram.
\end{abstract}

Estas concepções sobre a questão de gênero, vem sendo discutida, com o intuito de ampliar as noções da relação entre feminino e masculino, inserindo fundamentações que perpassam e superam o 'modelo patriarcal'. E neste âmbito, os processos escolares e as práticas educativas, tem sua função em recuperar os elementos históricos, além de buscar o rompimento do 'poder disciplinador', que por vezes, reafirma os espaços de homens e mulheres. Neste sentido, retoma-se a importância de inserção de documentos legais, como os plano de educação, para que tragam a abordagem das questões de gênero para o âmbito escolar. Uma vez que, como salienta Moreno (1999, p 57/58).

A mulher é a grande ausente nos textos escolares de história. Sua ausência fazse patente tanto nas descrições bélicas como nos escassos momentos em que se fala da organização social. Tudo isso nos indica que a mulher foi intensamente desconsiderada ao longo da história e que os livros de texto continuam desconsiderando-a, em uma desesperada tentativa de deter o passar do tempo. 
O desafio de compreender a lógica do conteúdo de gênero nesses documentos exige dois movimentos analíticos: um deles, voltado para o exame dos referidos documentos na perspectiva dos direitos e da construção da cidadania, não necessariamente da referência explícita à expressão gênero; o outro, dirigido à ideia abstrata de cidadania contida nos documentos, mas tomando a normatização neles prevista como expressão não só da permanência de costumes e formas de controle de um determinado momento histórico, mas também de propósitos que procuram dar novos significados à prática social.

Até porque, o Plano Municipal de Educação não aponta a questão da Ideologia de gênero, não há o uso deste termo, o que é equivocadamente utilizado por alguns grupos religiosos e ganha espaço na mídia. Pode-se afirmar que o Plano Nacional de Educação foi o resultado de ampla discussão com a sociedade civil, setores organizados no Fórum Nacional em Defesa da Escola Pública, apontando encaminhamentos de diferentes proposições para o trabalho educativo nos espaços escolares. Principalmente em relação a igualdade de direitos e equidade social, pois como afirma Carvalho, (1998, p. 21):

[...] para uma maior igualdade entre homens e mulheres no conjunto da sociedade, à medida que caminhar na direção de uma educação não sexista, que contribua para a superação de preconceitos e para a construção de pessoas comprometidas com a igualdade de direitos entre os sexos.

O conceito de gênero, visa sair de explicações das desigualdades fundamentadas sobre as diferenças físicas e biológicas, afirmando seu caráter social, histórico e político (Scott, 1992), remetendo a dinâmica da construção e da transformação social, aos significados que vão além dos corpos e dos sexos. Assim no espaço escolar é preciso compreender as identidades subjetivas e coletivas, ampliar as discussões sobre a identidade de gênero e dos grupos que resistem aos modelos dominantes de masculinidade e feminilidade. E um dos caminhos possíveis seria com a inserção nos Planos de Educação (Nacional, Estadual e Municipal).

Porém, mesmo com a retirada dos documentos legais, ainda há o processo de inserção na prática pedagógica através do comprometimento de educadores/as que perpassam as discussões pelos viés do respeito a diferença, as identidades de gênero, com o compromisso de uma escola que repense os estereótipos sexuais e de gênero. Como afirma Martinez (1997, p 266). 
[...] necessário introduzir a discussão das questões de gênero na formação de professores/as, no sentido de formar profissionais reflexivos que possam pensar e repensar sua própria prática, no sentido de conhecer a importância crescente que detém a linguagem (nas suas diversas formas: oral, escrita, corporal, etc.) na formação das identidades de gênero e na transmissão - ou não dos estereótipos sexuais. [...] A prática pedagógica crítica exige um compromisso com a transformação social, devendo examinar a escola mais de perto, persistentemente, em termos de questões de etnia, classe, poder, gênero e cultura.

De acordo com Louro (1997) as relações pedagógicas que são construídas na escola tem inúmeros caracterizações. É nestas relações que os estudantes aprendem normas, conteúdos, valores, significados, que lhes permitem interagir e conduzir-se de acordo com o gênero. Ainda na atualidade, percebe-se a influência de determinados costumes e padrões comportamentais, padronizados e que remetem a um modelo patriarcal.

Nesse sentido, a abordagem de gênero na escola pode significar o aprofundamento das dimensões históricas e subjetivas que envolvem as relações sociais e culturais. A discussão sobre gênero implica necessariamente compreender a dinâmica complexa da sociedade e, neste encaminhamento, o conceito de gênero é inserido pela perspectiva da história social e dos estudos das mulheres, como aponta Costa (2003, p 195), "os estudos das mulheres, a história social e a dos feminismos, aproximados, serão, agora, os lugares principais de assentamento do conceito de gênero".

São inúmeras problematizações sobre gênero que irrompem no cotidiano escolar, que inquietam os profissionais da história e da educação. São históricas as lutas pela superação das desigualdades em âmbito escolar, com esforços dos grupos de atuação nas escolas que tem nos documentos, o encaminhamento das garantias de diálogo e de estudos que permitem consolidar as ações educativas em torno da diversidade de gênero.

Uma das proposições, pensando no nosso campo de atuação, como profissionais da Educação e da História, se dá em problematizar o gênero a partir das relações diversificadas que se apresentam culturalmente no espaço escolar. Problematizar como nas aulas de História trabalha-se com os conceitos históricos sobre a relação entre homem e mulher, sobre as vivências e histórias de homossexuais, de transexuais, enfim, fundamentar discussões para além dos elementos de heteronormatividade. Assim, a abordagem sobre as questões de gênero pode ultrapassar as prescrições 'religiosas', 'patriarcais' e ampliam os elementos de análise sobre as relações entre as pessoas. 
Pensando nesta perspectiva, mesmo que o Plano Municipal de Educação tenha retirado a questão de gênero, há no campo da história a possibilidade de utilização das diretrizes dos Parâmetros Curriculares Nacionais. Mesmo que as discussões sobre gênero, estejam circunscritas ao campo da saúde e da sexualidade, possibilitam a inserção na aula de história. No texto dos PCN’s (Brasil, 1998 p.26):

[...] por serem questões sociais, os Temas Transversais têm natureza diferente das áreas convencionais. Tratam de processos que estão sendo intensamente vividos pela sociedade, pelas comunidades, pelas famílias, pelos alunos e educadores em seu cotidiano. São debatidos em diferentes espaços sociais, em busca de soluções e de alternativas, confrontando posicionamentos diversos tanto em relação à intervenção no âmbito social mais amplo quanto à atuação pessoal. São questões urgentes que interrogam sobre a vida humana, sobre a realidade que está sendo construída e que demandam transformações macrossociais e também de atitudes pessoais, exigindo, portanto, ensino e aprendizagem de conteúdos relativos a essas duas dimensões.

Entre as questões urgentes que interrogam a vida humana, está a abordagem de gênero, pois como defendem Soihet e Pedro (2007, p 289):

[...] 'gênero' dá ênfase ao caráter fundamentalmente social, cultural, das distinções baseadas no sexo, afastando o fantasma da naturalização; dá precisão à idéia de assimetria e de hierarquia nas relações entre homens e mulheres, incorporando a dimensão das relações de poder; dá relevo ao aspecto relacional entre as mulheres e os homens, ou seja, de que nenhuma compreensão de qualquer um dos dois poderia existir através de um estudo que os considerasse totalmente em separado, aspecto essencial para "descobrir a amplitude dos papéis sexuais e do simbolismo sexual nas várias sociedades e épocas, achar qual o seu sentido e como funcionavam para manter a ordem social e para mudá-la.

A compreensão das diferenças pode ampliar o sentimento de empatia entre os sujeitos, pode fundamentar olhares para o problema do outro, para as implicações cotidianas. Assim, no ensino de história, ao utilizar o texto do PCN para o Ensino Fundamental, amplia-se a abordagem sobre a noção de identidade, uma vez que "é primordial que o ensino de História estabeleça relações entre identidades individuais, sociais e coletivas”. (PCNS, 1997: p. 32).

Esse é um dos desafios no ensino de história, inserir as discussões sobre as relações de gênero numa perspectiva em valorize o coletivo, mas também as particularidades. Num processo mais aprofundando das concepções culturais que permeiam as identidades e diferenças e, de certa forma, impulsionando análises e produção do conhecimento histórico. 
Juçara Leite (2001) sugere uma metodologia que pode ser utilizada em sala: o resgate do trabalho do historiador-pesquisador com suas fontes. Ela ressalta que é importante "desenvolver atitudes investigativas" que problematizem os conteúdos, criando assim o conhecimento escolar. Considera que as inclusões das discussões de gênero em livros didáticos foram feitas de forma precária e "sem integração com os chamados conteúdos tradicionais". A historiadora exemplifica dois procedimentos que podem ser feitos em sala com o uso crítico do livro didático (LEITE, 2001, p 132):

[...] o primeiro deles, que pode ser realizado com alunos pequenos, consiste em pedir que os estudantes observem no livro imagens de brincadeiras do passado e do presente. Deve-se separar as que mostram meninas brincando e refletir com os alunos os desdobramentos em relação a isto, como é o caso das claras diferenças entre os gêneros.

A busca fontes documentais pouco convencionais pode apoiar o ensino da história, em direção a muitas descobertas, como afirma Suely Costa (2002, p, 08):

Livros de receitas domésticas, de alimentos e/ou remédios caseiros, quanto contém de práticas familiares de subsistência, de associativismos informais peculiares à história política do feminino, de processos societários impensáveis. Acessar fontes históricas as mais variadas, usar documentos de muitos tipos, estimular a busca regular de leitura de documentos históricos objetos vários - evidenciam práticas sociais desapercebidas, forma de reinventar o modo de pensar a história.

Em suma, ampliar as noções de gênero no ensino e principalmente na história ensinada, possibilita estimular a investigação sobre os diferentes sujeitos envolvidos nos processos históricos, numa busca pela história ensinada/aprendida que integre o conhecimento histórico sobre as relações de gênero na História. E que, se torne uma História que narre sobre os sujeitos em sua alteridade, de forma crítica, em que a abordagem do processo histórico, apresente que a disciplina de História poderá ter a função de "preparar para considerar questões complexas" (MATOSO, 1999: 12).

Assim, podemos pensar problematizar as consequências que emergem das relações de poder/hierarquias de gênero no âmbito escolar, bem como nas aulas de História. Além disso, pensar projetos integrados que envolvam as concepções de gênero na história e historiografia, analisar um contexto específico, em que os eixos temáticos possam possibilitar a reflexão sobre o caráter cultural das relações de gênero. Sobre isso, a produção de estudos de gênero tem implicação direta nas concepções culturais, pois as referências culturais são produzidas por 
símbolos, jogos de significação, cruzamento de conceitos e relações de poder, conceitos normativos, relações de parentesco, econômicas e políticas (MATTOS, 2000, p.17).

Desta maneira, as identidades ou subjetividades de gênero estão imersas nos constructos sociais e culturais, englobando discursos, práticas, representações, estereótipos. E em que as construções subjetivas e as formas de organizar na sociedade, as disputas e a manutenção dos espaços que permitam ao sujeito ser 'ele mesmo', tenham também no espaço escolar e nas aulas de história a necessária visibilidade.

\section{CONSIDERAÇÕES E AGRURAS}

Quando iniciamos esse artigo, pensamos em apontar o contexto do Plano Municipal de Educação de Campo Grande e os discursos intervencionistas de grupos religiosos, que aquém da discussão pontuada por profissionais da Educação, pautavam-se em 'exigir' a retirada da questão de gênero. Isso nos evidenciou como as políticas educacionais não são pensadas como políticas públicas, que atendam as demandas sociais e culturais. Uma vez que, em nenhum momento da discussão sobre a 'retirada' do texto sobre gênero do PME, foi levado em conta os dados de 'expulsão compulsória' da escola, dos estudantes que não se veem e não se enquadram nos padrões heteronormativos.

Além disso, todo o processo de estudo realizado, as pautas e análises feitas pela Secretaria de Educação foram suprimidas na votação da câmara de vereadores. O que nos impulsiona a fundamentar as abordagens de gênero por outros documentos oficiais, como os Parâmetros Curriculares Nacionais, que, por sua vez ampliam as perspectivas de análise, mas podem ser um caminho, na tentativa de permitir que as vozes silenciadas/abafadas, se façam ouvir por aqueles que discursam em nome do 'moralismo e do patriarcado'. Pois, a questão de gênero, sexualidades, etnia e raça têm sido colocados na agenda pública, chegando às escolas como políticas de inclusão (SEFFNER, 2013)

Em relação as políticas públicas percebe-se, como no caso do Plano Municipal de Educação em Campo Grande, a preocupação dos grupos religiosos em estabelecer o que seria trabalhado na escola, evidencia um 'olhar estereotipado' sobre gênero e sexualidade. E, ainda mais, evidencia o quanto o desenvolvimento do aprendizado no âmbito escolar é perpassado pelo externo a escola, por grupos conservadores, políticos conservadores que enveredam por se intrometer no currículo. O que nos leva a pensar que, a produção do conhecimento escolar deve sensibilizar os sujeitos para as dimensões de gênero no cotidiano social e escolar. Desta 
maneira, o desenvolvimento de políticas públicas de educação que pense na redução da desigualdade de gênero na sociedade brasileira, "é ainda escassa e segue a tendência geral das pesquisas de gênero na educação, caracterizadas pela precária divulgação" (ROSEMBERG, 2001).

Em suma, mais do que inserir temas voltados à diversidade de gênero no âmbito escolar, é necessário sensibilizar os educadores/as, bem como a sociedade, para superar as dificuldades que as pessoas passam devido as identidades de gênero.

E, trazer para o centro do debate, as reflexões sobre a produção de sentido histórico em abordar a questão de gênero, fundamentando em políticas públicas e também os seus significados ao longo da história. Nesse sentido, retomamos as concepções de Scott (1990, p.14) de que o: "o gênero é um elemento constitutivo de relações sociais fundadas sobre as diferenças percebidas entre os sexos e o gênero é um primeiro modo de dar significado às relações de poder”. O que de certa forma, amplia os 'olhares' da história e na história dos grupos culturais e suas identidades de gênero.

\section{REFERÊNCIAS BIBLIOGRÁFICAS}

BOCK, Ana M. Bahia; FURTADO, Odair; TEIXEIRA, Maria de Lourdes. Psicologias: uma introdução ao estudo de psicologia. 13.ed. São Paulo: Saraiva, 2001.

CARVALHO, M. P. Um olhar de gênero sobre as políticas educacionais. In: FARIA, N.; NOBRE, M.; AUAD, D. et al. (Orgs.). Gênero e educação. São Paulo: SOF, 1999. p. 9-24.

COSTA, Suely Gomes. Conceito de gênero e ensino de história. ANPUH RJ, 2002.

DERMEVAL. Saviani. Sistemas de ensino e planos de educação: O âmbito dos municípios. Educação \& Sociedade, ano XX, nº 69, Dezembro/99.

GANDELMAN, Luciana M. "Gênero e Ensino: parâmetros curriculares, fundacionismo biológico e teorias feministas". In: ABREU, Martha; SOIHET, Rachel. Ensino de História: conceitos, temáticas e metodologia. Rio de Janeiro: Casa da Palavra, 2009, p. 209.

LEITE, Juçara. Fazendo gênero na história ensinada: uma visão além da (in)visibilidade. In: Secretaria de Educação Básica. Coleção Explorando o Ensino- História, Ensino Fundamental. Volume 21. 2010, p.201.

LOURO, Guacira Lopes; FELIPE, Jane; GOELLNER, Silvana Vilodre (Org.). Corpo, gênero e sexualidade: um debate contemporâneo na educação. Editora Vozes: Petrópolis/RJ, 2008.

. Gênero e sexualidade: pedagogias contemporâneas. Revista Pro-Posições, v. 19, n. 2 (56)

- maio/ago. 2008

O corpo educado: Pedagogias da Sexualidade. $2^{\text {a }}$ Edição. Belo Horizonte, 2000 

n. 2, 1995.

Gênero, História e Educação: construção e desconstrução. Educação \& Realidade, v. 20, 1997.

Gênero, sexualidade e educação: uma perspectiva pós estruturalista. Petrópolis: Vozes,

MATTOS, M. Reinvenções do vínculo amoroso: cultura e identidade de gênero na modernidade tardia. Belo Horizonte: Ed. UFMG; Rio de Janeiro: IUPERJ, 2000.

MATTOSO, J. (1999), A Função Social da História no Mundo de Hoje, Lisboa, A.P.H. Le Goff, Jacques, Nora, Pierre (dir.) (1977-1978), Fazer História, 3 vols., Venda Nova, Bertrand.

MARTINEZ, S. A. Questões de gênero e formação de professores/as. In: CANDAU, V.M. (Org.). Magistério: construção cotidiana. Petrópolis: Vozes, 1997.

MORENO, M. Como se ensina a ser menina: o sexismo na escola. São Paulo: Moderna, 2003

PEDRO, Joana M. Relações de gênero como categoria transversal na historiografia contemporânea. Topoi, v. 12, n. 22, jan.-jun. 2011, p. 270-283.

PINTO, Teresa. Género e Recursos Educatios Digitais de História. Género e Recursos Educativos Digitais, Lisboa, DGIDC, 2011, p. 11-18.

ROSEMBERG, F. Caminhos cruzados: educação e gênero na produção acadêmica. Educação e Pesquisa, São Paulo, v.27, n.1, p.47-68, 2001.

SEFFNER, Fernando. Sigam-me os bons: apuros e aflições nos enfrentamentos ao regime da heteronormatividade no espaço escolar. Educação e Pesquisa, v. 39, n. 1, p. 145-159, jan./mar. 2013.

SOUZA, Rosa. Itinerários da pesquisa sobre a cultura escolar In: CUNHA, Marcus. Ideário e imagens da educação escolar. Campinas: autores associados, 2001.

SOIHET, Rachel. Violência simbólica. Saberes masculinos e representações femininas. Estudos Feministas, v.5, n.1, p.7-29, 1997.

SOIHET, Raquel; PEDRO, Joana Maria. A emergência da pesquisa da História das Mulheres e das Relações de Gênero. Revista Brasileira de História. São Paulo, v. 27, nº 54, p. 281-300 2007. 